\title{
Cytological and Molecular Characterization of ZmWAK-Mediated Head-Smut Resistance in Maize
}

\author{
Nan Zhang, ${ }^{1,3}$ Boqi Zhang, ${ }^{1}$ Weiliang Zuo, ${ }^{1}$ Yuexian Xing, ${ }^{2}$ Suvimon Konlasuk, ${ }^{1}$ Guoqing Tan, ${ }^{2}$ \\ Qianqian Zhang, ${ }^{1}$ Jianrong $Y e,{ }^{1}$ and Mingliang $X u^{1}$ \\ ${ }^{1}$ National Maize Improvement Centre of China, China Agricultural University, Beijing 100193, People's Republic of China; \\ ${ }^{2}$ Maize Research Institute, Jilin Academy of Agricultural Sciences, Gongzhuling, Jilin 136100, People's Republic of China; and \\ ${ }^{3}$ Crops Research Institute, Guangdong Academy of Agricultural Sciences, Guangdong Provincial Key Laboratory of Crops \\ Genetic \& Improvement, Guangdong 510640, People's Republic of China
}

Accepted 16 March 2017.

\begin{abstract}
Head smut, caused by the fungal pathogen Sporisorium reilianum, poses a threat to maize production worldwide. $\mathrm{ZmWAK}$, a cell wall-associated receptor kinase, confers quantitative resistance to head smut disease. Here, two near-isogenic lines (NILs), susceptible line Huangzao4 and its $\mathrm{ZmWAK}$-converted resistant line Huangzao4R, were used to decipher the role of ZmWAK in head smut resistance. Cytological and molecular characterization in response to $S$. reilianum infection was compared between two NILs. Upon S. reilianum infection, the growth of pathogen hyphae was severely arrested in the $Z m W A K$-converted resistant line Huangzao4R, relative to its susceptible parental line Huangzao4. Infected cells exhibited apoptosis-like features in Huangzao4R and hyphae were sequestered within dead cells, whereas pathogen invasion caused autophagy in Huangzao4, which failed to prevent hyphal spreading. Integrated transcriptomic and metabolomic analysis indicated that $\mathrm{ZmWAK}$ functions as a hub in the trade-off between growth and defense, whereby $\mathrm{ZmWAK}$ promotes cell growth in the absence of the pathogen and switches to a defense response upon $S$. reilianum attack. These findings shed light on an elegant regulatory mechanism governed by $\mathrm{ZmWAK}$ in the trade-off between growth and head smut defense.
\end{abstract}

Head-smut disease, caused by Sporisorium reilianum, poses a devastating threat to maize production worldwide. Teliospores in soil or plant debris serve as the initial source of infection. Under favorable soil conditions, teliospores germinate into yeast-like haploid basidiospores to form sporidia. When compatible, haploid sporidia mate to form infectious dikaryotic hyphae (Martinez et al. 2002). Filamentous hyphae enter maize during seedling emergence and grow in a prolonged biotrophic phase, until invading the floral meristems, in which $S$. reilianum transforms into its destructive necrotrophic form (Martinez et al. 1999, 2002). Maize suffering from head smut displays diverse malformations such as stunted plants, loss of apical dominance, numerous tillers, phyllody in the inflorescences, and excessive ears, among others. The classic symptom is that tassels and ears are partly or completely replaced by large smut

Corresponding author: M. Xu: Telephone: +1 86-10-62733166,

Fax: +1 86-10-62733808; E-mail: mxu@ cau.edu.cn

*The $\boldsymbol{e}$-Xtra logo stands for "electronic extra" and indicates that five supplementary figures and seven supplementary tables are published online.

(c) 2017 The American Phytopathological Society galls. Differences in these morphologic deformities likely depend on the developmental stage of the inflorescence when S. reilianum colonizes maize seedlings (Ghareeb et al. 2011). When galls rupture, new spores are released and dispersed by wind and contaminate soil, thereby perpetuating the next life cycle.

Zea mays WAK (ZmWAK), a quantitative disease-resistance gene, confers resistance to head-smut disease (Zuo et al. 2015). ZmWAK contains a cytoplasmic serine/threonine kinase domain, a calcium-binding epidermal growth factor domain, and an extracellular galacturonan-binding domain; hence, ZmWAK belongs to the wall-associated kinase (WAK) family (Zuo et al. 2015). Genes of the WAK family have tended to expand among plant species during evolution (de Oliveira et al. 2014; He et al. 1999; Verica and He 2002; Zhang et al. 2005). Given the presence or absence of the conserved arginine (R) adjacent to the catalytic aspartate (D), WAK proteins can be divided into two evolutionarily related subfamilies, i.e., RD WAK and nonRD WAK, the latter of which is restricted to monocots (de Oliveira et al. 2014). Unlike the well-studied WAK proteins in Arabidopsis, ZmWAK is a typical monocot non-RD kinase (Zuo et al. 2015). Moreover, the novel non-RD WAK family member ZmWAK-RLK1 (receptor-like kinase 1) of maize was identified based on its ability to improve resistance to northern corn leaf blight (Hurni et al. 2015). In Arabidopsis, WAK proteins serve as receptors for two kinds of ligands, namely, native pectin and its degradation products, oligogalacturonic acids (OGs) (Brutus et al. 2010; Decreux and Messiaen 2005; Kohorn et al. 2009). A previous review envisioned a model for the perception of ligands by WAK proteins (Kohorn 2016), that is, the recognition of native pectin activates the mitogen-activated kinase (MAPK) MPK3 and maintains cell expansion under normal growth conditions, whereas WAK proteins sense cellwall damage, bind pectin fragments, and evoke MPK6-mediated stress signaling under stress (Kohorn 2016; Kohorn et al. 2012).

Programmed cell death (PCD) is a highly conserved and fundamental program that requires precise management of the cell death systems. Apoptosis-like PCD (AL-PCD) and autophagy constitute two forms of plant PCD that are governed by distinct molecular pathways and have remarkably distinct morphologic features (Dickman and Fluhr 2013). AL-PCD is an irreversible endogenous self-killing process that manifests distinct features, including cell shrinkage, membrane blebbing, nuclear condensation and fragmentation, and DNA laddering (Reape and McCabe 2008, 2010). The BAG (Bcl-2 athanogene) family, homolog to the mammalian BAG family, regulates ALPCD in plants (Doukhanina et al. 2006). Autophagy is the 
process by which cellular components are degraded and recycled (Liu and Bassham 2012). Cellular cargo is packaged by a double-membrane structure, termed the autophagosome, and becomes destined for degradation in vacuoles. Autophagy requires collaboration among specific autophagy-related genes (Atgs). In plant-microbe interactions, PCD can benefit or harm the plant depending on the pathway by which host cells die (Dickman and Fluhr 2013). Infection with the necrotrophic pathogen Sclerotinia sclerotiorum triggers AL-PCD, which promotes disease (Dickman et al. 2001). Overexpression of the antiapoptotic BCL-2 family protein CED-9 from Caenorhabditis elegans was found to reduce cell death and increase resistance to S. sclerotiorum (Kim et al. 2008). The S. sclerotiorum oxalic acid-deficient nonpathogenic A2 mutant could generate autophagy in the host and restrict lesion expansion (Kabbage et al. 2013; Williams et al. 2011).

We previously found that $Z m W A K$ confers head-smut resistance by arresting $S$. reilianum growth in the mesocotyl, a structure in which $Z m W A K$ is highly expressed (Zuo et al. 2015). Despite progress made on defining the functions of WAK proteins, the mechanism underlying $Z m W A K$-mediated head-smut resistance remains to be fully understood. In the current study, we used two near-isogenic lines (NILs) - a susceptible line Huangzao4, which lacks a functional $Z m W A K$, and its $Z m W A K$ converted resistant line Huangzao4R - to decipher the cytological and molecular mechanisms underlying ZmWAK-dependent maize resistance to head-smut disease. Our findings highlighted that an intriguing switch between cell growth and AL-PCD was monitored by ZmWAK, which suggest that ZmWAK promote cell growth under normal growth circumstances and activate AL-PCD to restrict hyphal growth, leading to subsequent headsmut resistance upon $S$. reilianum invasion.

\section{RESULTS}

\section{ZmWAK-triggered hypersensitive response (HR)-like PCD restricts $S$. reilianum invasion in mesocotyls.}

To gain a whole-plant view of ZmWAK function, seeds from two NILs were sowed in soil mixed with $S$. reilianum inoculum and were grown in an illumination incubator to mimic natural infection. Infected mesocotyls were collected from the two NILs at different time points after pathogen inoculation (Fig. 1A). At 7 days after sowing (DAS), mesocotyls of Huangzao4 appeared symptomless, whereas a handful of Huangzao4R mesocotyls showed small and restricted lesions, resembling HR-like cell death (Fig. 1A and B). By 14 DAS, Huangzao4 mesocotyls had shrunk and some of the cells had died, whereas Huangzao4R mesocotyls appeared essentially the same as observed at 7 DAS. At 21 DAS, Huangzao4 mesocotyls exhibited severe damage with brownish discoloration and necrosis, whereas Huangzao4R mesocotyls still had a few lesions. A key step to guarantee the pathogenic success of $S$. reilianum is its colonization of shoot apical meristems (SAMs) (Ghareeb et al. 2011), and thus, the presence or absence of $S$. reilianum in SAMs was investigated, via polymerase chain reaction (PCR) at 21 DAS (before the floral transition), with the $S$. reilianum-specific primer SRac. The infection rate was strikingly different between the two NILs; for Huangzao4, 45\% $\pm 6 \%$ of SAMs were infected, which was significantly greater
A

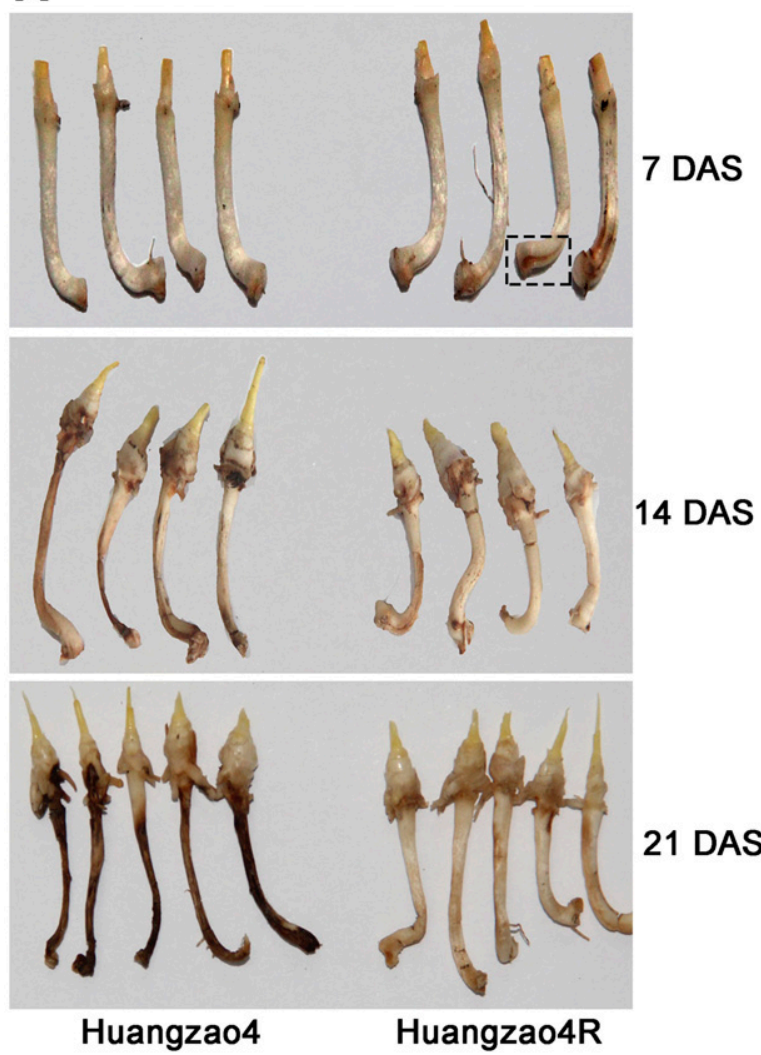

B

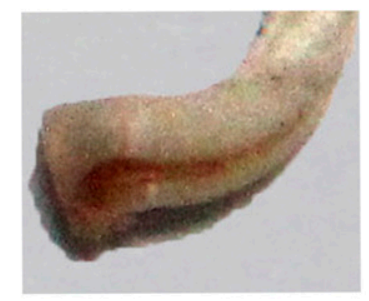

C

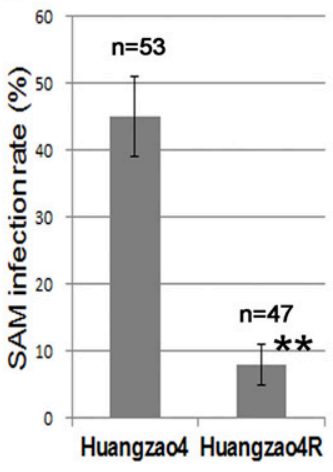

Fig. 1. ZmWAK restricts Sporisorium reilianum from gaining access to shoot apical meristems (SAMs). A, Time course of symptom development of mesocotyls in response to $S$. reilianum colonization. B, Enlarged view of the dashed rectangle in A (7 days after sowing [DAS]) showing hypersensitive response-like programmed cell death of epidermal cells from Huangzao4R mesocotyls. C, Rate of $S$. reilianum invasion of SAMs in Huangzao4 and Huangzao4R. SAMs were collected at 21 DAS. Three independent experiments were conducted, $\mathrm{n}=$ number of plants investigated. The error bars denote standard error. Asterisks (**) indicate $P<0.01$ (Student's $t$ test). 
than the $8 \% \pm 3 \%$ for Huangzao4R (Fig. 1C). The difference in mesocotyl morphological features and SAM invasion rates implied that hyphal growth status differed between these two NILs.

We used wheat germ agglutinin (WGA) staining to visualize the dynamic infection process under a fluorescence microscope. At 4 DAS, dikaryotic filamentous hyphae were observed on the bottom surface of mesocotyls (Supplementary Fig. S2). At 5 DAS, copious hyphae were present on the surface, which initiated penetration into epidermal cells. In this regard, there was no significant difference between the two NILs at the initial infection stage, and only at 7 DAS were there noticeable differences. Whereas $S$. reilianum hyphae expanded steadily in Huangzao4, they were impeded after early invasion of a few epidermal cells in Huangzao4R (Fig. 2A). We further adopted scanning electron microscopy to assess hyphal growth in detail in the two NILs. At 7 DAS, hyphae grew aggressively in Huangzao4, as shown in both transverse and longitudinal sections, whereas invading hyphae were sequestered in necrotic areas in Huangzao4R (Fig. 2B). Trypan blue was used to examine both cell viability and hyphal growth (Fig. 2C). In Huangzao4R, HR-like cell death occurred in the colonized areas, in which hyphae were confined to dead cells. In Huangzao4, however, hyphae spread extensively across living cells, implying ongoing interactions between pathogen and host. Calculation of $S$. reilianum-infected NILs at 7 DAS revealed that Huangzao4R had a significantly higher rate of HRlike cell death response than Huangzao4 (Fig. 2D). High expression of $Z m W A K$ in the mesocotyl channel restricted hyphae access to SAMs by inhibiting hyphal growth in Huangzao4R, but this did not occur in Huangzao4 because it lacks functional $\mathrm{ZmWAK}$ (Zuo et al. 2015).

\section{Distinct cell death modes between the two NILs.}

S. reilianum induced acute cell death within infected areas of Huangzao4R, in contrast to the latent and prolonged cell death observed in Huangzao4 (Fig. 1). Distinct cell fates between Huangzao4 and Huangzao4R prompted us to wonder whether different modes of PCD occurred in these two NILs. Transmission electron microscopy was performed on the two NILs at 7 DAS to seek ultrastructural evidence for the distinction between the PCD processes. In infected Huangzao4, cells underwent autophagy with typical double-membrane autophagic structures (Fig. 3A to C). Infected Huangzao4R, however, exhibited diagnostic features of AL-PCD, such as nuclear condensation and chromatin fragmentation, cell shrinkage, and plasma membrane blebbing (Fig. 3D to F). Large vacuoles were present within S. reilianum hyphae in the infected Huangzao4 but not in the infected Huangzao4R. Moreover, the infected Huangzao4R showed swollen mitochondrion and plasma membrane contraction from the cell wall, vacuole rupture, and peroxisome emergence (Supplementary Fig. S3). Both infected NILs were also stained with the fluorescent dye monodansylcadaverine (MDC), an autophagosome marker (Supplementary Fig. S4). MDC-marked autophagosomes were observed only in infected Huangzao4. These data indicated that Huangzao4 underwent autophagy while Huangzao4R underwent

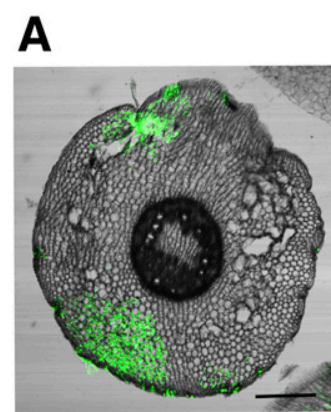

Huangzao4

B

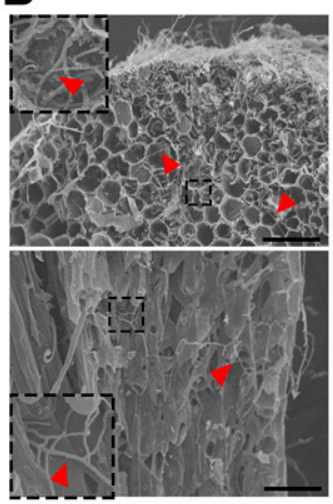

Huangzao4

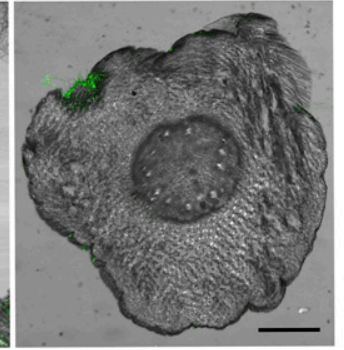

Huangzao4R

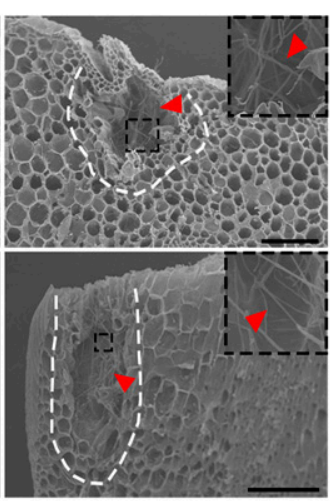

Huangzao4R

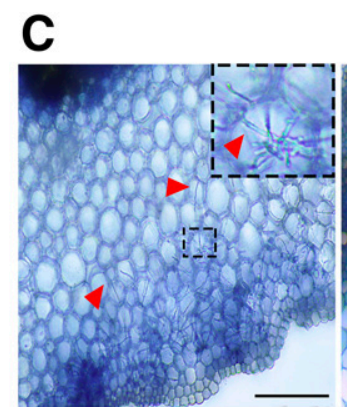

Huangzao4

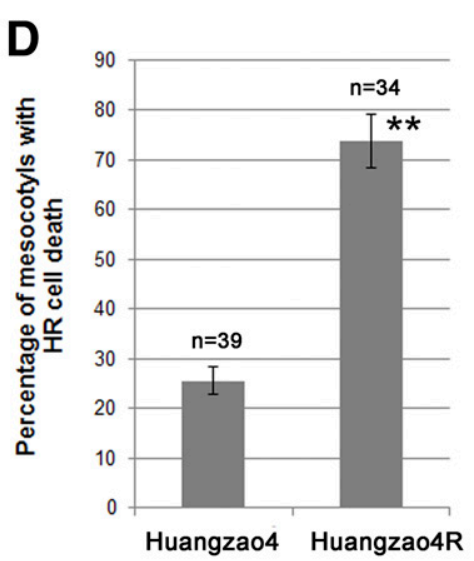

Fig. 2. Hypersensitive response (HR)-induced cell death restricts Sporisorium reilianum growth. A, Confocal images of S. reilianum invasion of Huangzao4 and Huangzao4R. S. reilianum hyphae were stained with wheat germ agglutinin, and samples were taken 7 days after sowing and were assessed for green fluorescent protein fluorescence. Images were merged with differential interference contrast images. Scale bars $=1 \mathrm{~mm}$. B, Scanning electron microscopy images of introgressed hyphae for both transverse and longitudinal sections. Red arrowheads denote $S$. reilianum hyphae. The white dashed line denotes the area of necrosis, in which hyphae were sequestered. Scale bars $=100 \mu \mathrm{m}$. C, Trypan blue staining for both hyphae and cell viability. Red arrowheads denote $S$. reilianum hyphae. White dashed lines denote the areas of necrosis. Scale bars $=100 \mu \mathrm{m}$. D, Calculation of HR-like cell death in the two near-isogenic lines. Mesocotyls were taken 7 days after sowing, samples were hand cut and were observed under a light microscope. Three independent experiments were carried out, and the mesocotyls with HR cell death is expressed as a percentage. $\mathrm{n}=$ number of plants investigated. The error bars denote standard error. Asterisks (**) indicate $P<0.01$ (Student's $t$ test). 
AL-PCD upon $S$. reilianum infection, $Z m W A K$ introgression leads to the activation of cellular AL-PCD machinery in Huangzao4R.

\section{A transcriptional switch between growth and defense was regulated by $Z m W A K$.}

Given the alternative cell-death strategy between two NILs, we were interested to discover the specific role that $Z m W A K$ played in response to $S$. reilianum invasion at the transcriptional level (Table 1). Global transcript profiling was performed to investigate $Z m W A K$-associated transcriptional changes. Mesocotyls from the two NILs, with or without $S$. reilianum infection, were taken at 7 DAS. Differentially expressed genes (DEGs) between the two NILs or between treatments were defined as genes having a $\log _{2}$-fold change of $>1$ and false discovery rate of $<0.01$, the DEGs were functionally annotated with MAPMAN BIN (barcode index number). The $Z m W A K$-associated response could be classified as a basal response (DEGs observed in noninfected mesocotyls) or defense response (DEGs between noninfected and infected mesocotyls). Supplementary Table S1 lists all the DEGs, and Figure 4 summarizes the observed transcriptional changes.

A comparison of noninfected mesocotyls between Huangzao4 and Huangzao4R allowed us to assess the ZmWAK-associated basal response (Supplementary Table S2). A total of 1,526 DEGs were identified as unique to Huangzao4R, of which 811 were up-regulated and 715 down-regulated. BIN enrichment analysis indicated significant over-representation of DEGs involved in cell-wall organization (cellulose synthase), cell wall-loosening agents (expansions and xyloglucan endotransglycosylase/hydrolase), and cell-wall arabinogalactans. Additionally, DEGs were also enriched in cell viability, i.e., cell cycle, cell division, cellular organization, and vesicle transport. Upregulated DEGs related to the cell cycle and cell-wall biosynthesis indicated that ZmWAK promotes cell growth. Consistent with growth promotion, genes for sugar and fatty-acid biosynthesis were enriched in Huangzao4R. Genes involved in signal transduction (calcium signaling, MAPK cascade, G-protein signaling) were also upregulated. MPK3 was up-regulated during the $Z m W A K$-associated basal response, which is similar to the AtWAK-associated growth response. On the other hand, the ZmWAK-associated basal response resulted in repression of genes involved in the biosynthesis of secondary metabolites (flavonoids, terpenoids, phenylpropanoids), production of reactive oxygen species (peroxidase, cytochrome P450), biotic stress response, and glycolysis. With regard to hormone signaling, ZmWAK promoted the expression of a set of genes that control auxin transport and response (AUX, GH3, PIN, and SAUR). Key genes involved in abscisic acid (ABA) biosynthesis (NCED9) and response ( $A B I$ and $H A I)$ were upregulated. Transcripts involved in the jasmonic acid (JA) (JAZ, $M Y C 2$ ) and ethylene (ET) biosynthesis (1-aminocyclopropane-1carboxylate $[\mathrm{ACC}]$ synthase) and signaling pathways (ERF/AP2)

Table 1. RNAseq read counts and read mapping to the maize genome

\begin{tabular}{lcccccc}
\hline & & \multicolumn{3}{c}{$\begin{array}{c}\text { Mapped to maize } \\
\text { genome }\end{array}$} & & \multicolumn{2}{c}{ Unique reads } \\
\cline { 3 - 4 } Sample & All reads & Reads & Rate & & Mapped & Rate \\
\hline HZ4C-1 & $44,764,682$ & $33,464,141$ & $74.76 \%$ & & $28,586,092$ & $63.86 \%$ \\
HZ4C-2 & $43,825,910$ & $31,831,040$ & $72.63 \%$ & & $26,236,353$ & $59.86 \%$ \\
HZ4RC-1 & $42,011,266$ & $32,608,605$ & $77.62 \%$ & & $27,582,138$ & $65.65 \%$ \\
HZ4RC-2 & $41,705,354$ & $32,318,571$ & $77.49 \%$ & $26,945,178$ & $64.61 \%$ \\
HZ4I-1 & $40,191,622$ & $27,897,122$ & $69.41 \%$ & $23,647,272$ & $58.84 \%$ \\
HZ4I-2 & $30,120,716$ & $20,855,446$ & $69.24 \%$ & $16,406,790$ & $54.47 \%$ \\
HZ4RI-1 & $37,247,598$ & $28,711,029$ & $77.08 \%$ & $20,541,787$ & $55.15 \%$ \\
HZ4RI-2 & $35,483,886$ & $27,473,459$ & $77.43 \%$ & $20,575,789$ & $57.99 \%$ \\
\hline
\end{tabular}
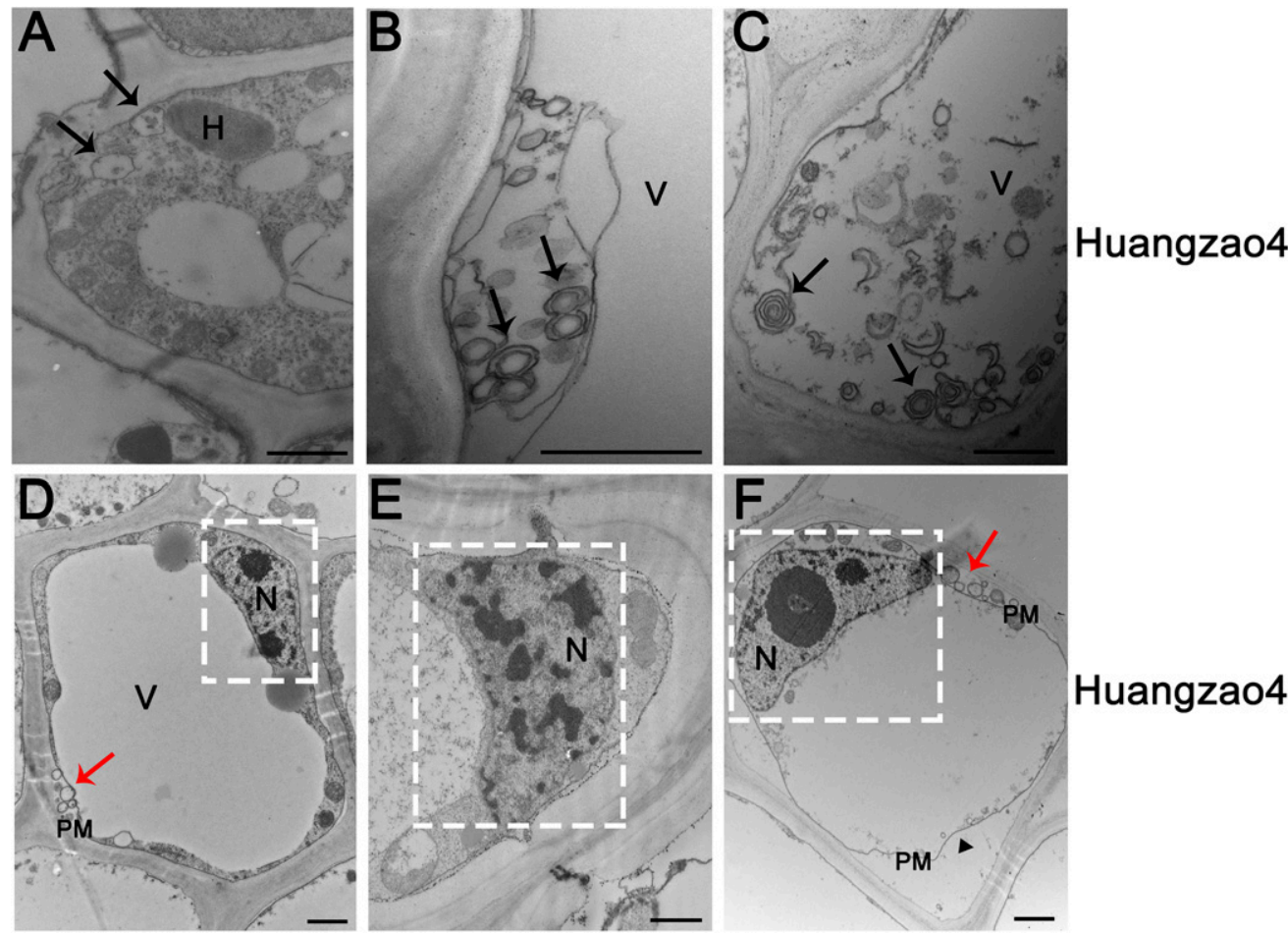

Fig. 3. Different cell death strategies between two near-isogenic lines in response to Sporisorium reilianum infection. A, B, and C, Transmission electron microscopy images of $S$. reilianum-infected Huangzao4. Black arrows indicate autolysosome/autophagosome-like structures. D, E, and F, S. reilianuminfected Huangzao4R. Dashed rectangles indicate nuclear condensation and chromatin fragmentation. Red arrows indicate plasma membrane blebbing. The black arrowhead indicates plasma membrane contraction from the cell wall. All samples were taken 7 days after sowing. $\mathrm{H}=\mathrm{hyphae} ; \mathrm{V}=\mathrm{vacuole}, \mathrm{N}=$ nucleus, and $\mathrm{PM}=$ plasma membrane. Scale bars $=1 \mu \mathrm{m}$ 
were also strongly elevated. Salicylic acid (SA) biosynthesis gene $(P A L)$ and salicylic acid-induced pathogenesis-related (PR) proteins were strongly down-regulated. Genes involved in gibberellic acid (GA) biosynthesis (GA2 and GA3) were repressed whereas genes that deactivate GA $(G A 2 O X)$ were elevated. This $Z m W A K$ associated basal response suggested that ZmWAK action generally results in the allocation of more energy/metabolites for growth and development and less for biotic stress responses.

To explore the $Z m W A K$-associated defense response, we compared transcriptomic changes between infected and noninfected mesocotyls for both Huangzao4R and Huangzao4. A total of 2007 DEGs were identified for Huangzao4R compared
A

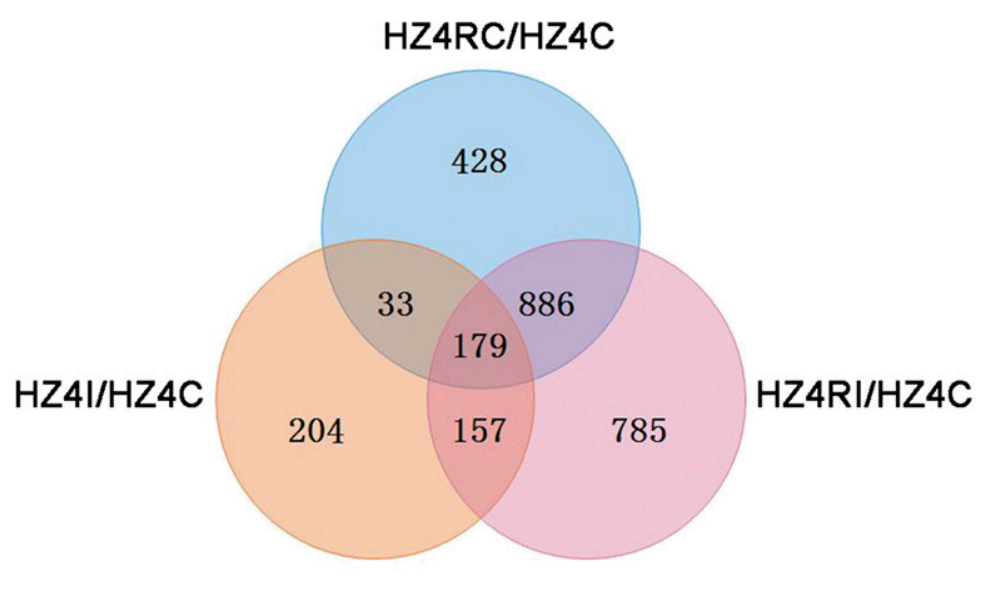

C

ZmWAK-associated basal response

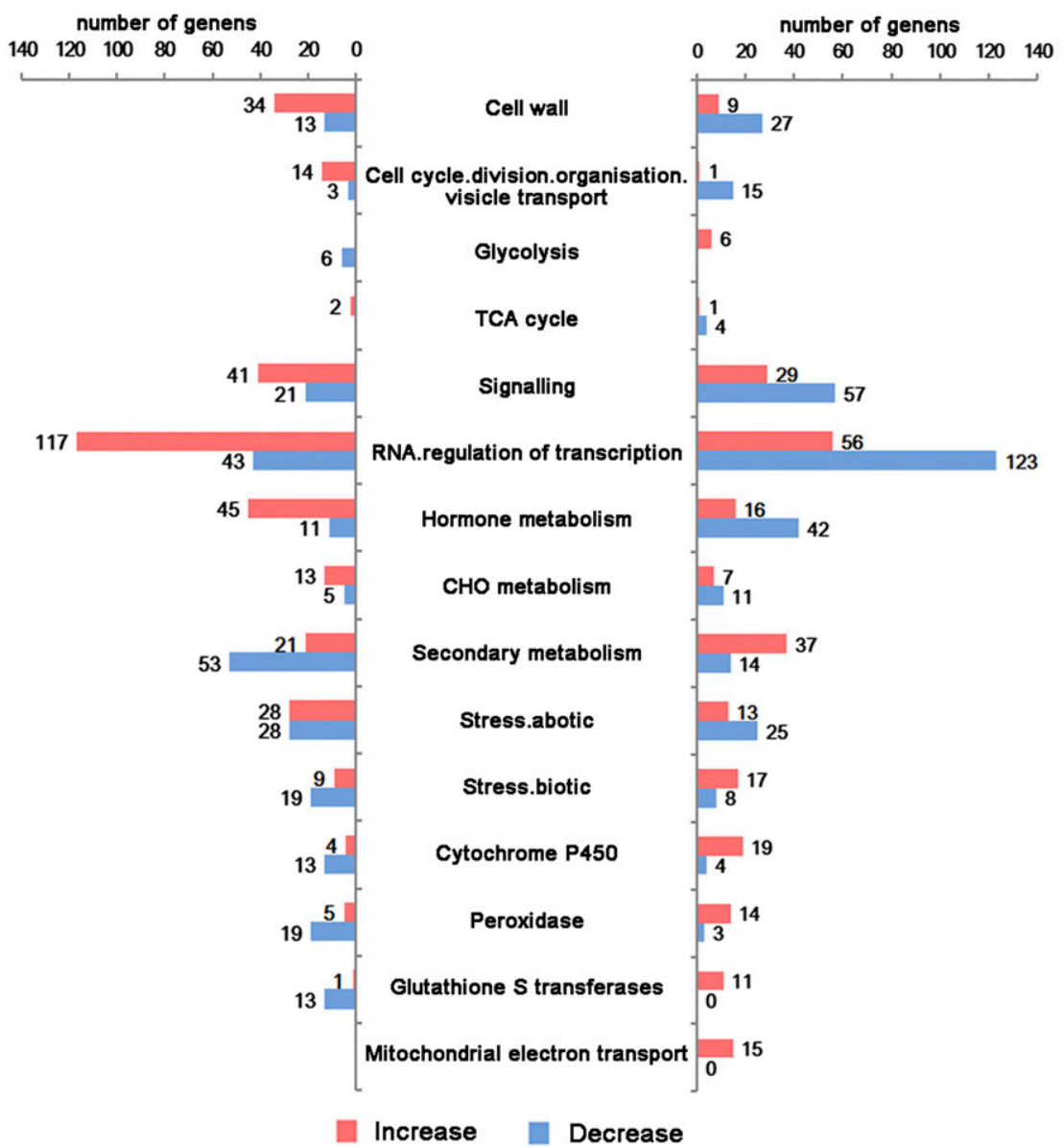

B
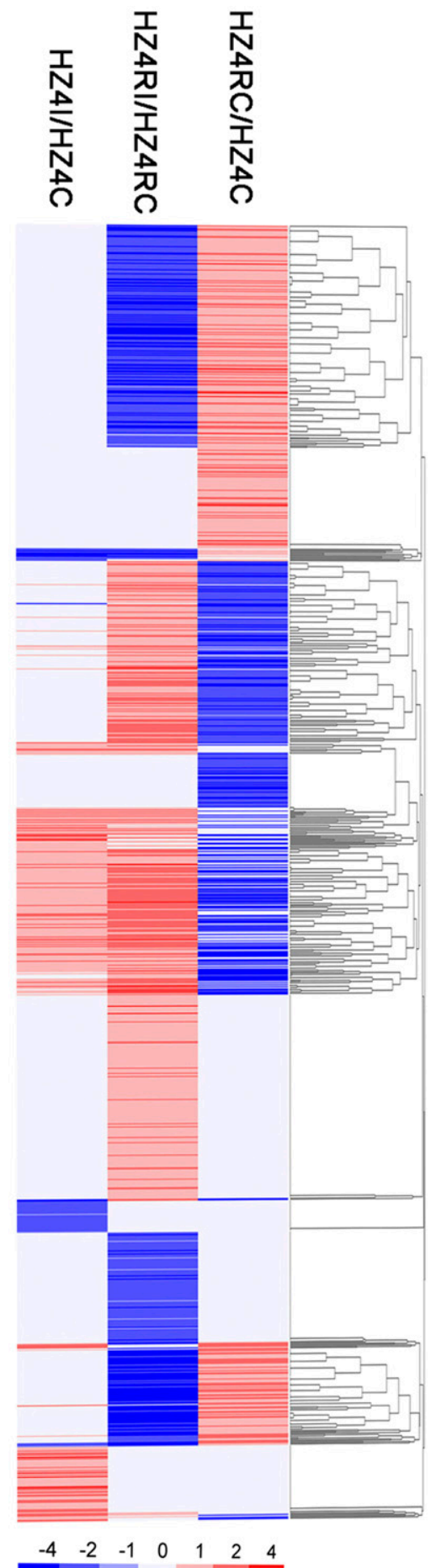

Fig. 4. Transcriptome analysis of Huangzao4 and Huangzao4R with or without Sporisorium reilianum infection A, Venn diagram illustrating the number of DEGs present in three pairs of samples: HZ4C/HZ4RC, HZ4I/HZ4C, and HZ4RI/HZ4RC (fold change $>2, P<0.01$ ), and the overlapping DEGs among the three comparisons. B, Heatmap showing those Differentially expressed genes present in at least one of the three comparisons. Fold changes were $\log _{2}-$ transformed, and the data represent the average from two biological replicates. $\mathbf{C}$, The number of genes that were significantly different in ZmWAK-associated basal response and ZmWAK-associated defense response. HZ4C = noninfected Huangzao4, HZ4RC = noninfected Huangzao4R, HZ4I = infected Huangzao4, and HZ4RI = infected Huangzao4R. 
with 573 DEGs for Huangzao4. After eliminating 336 DEGs in common, the remaining 1671 DEGs, of which 797 were upregulated and 874 down-regulated, were assigned to $\mathrm{ZmWAK}$ associated defense response (Supplementary Table S3). Surprisingly, up to 886 DEGs showed opposite enrichment between the ZmWAK-associated basal and defense responses (Fig. 4B and 4C), implying a contrasting role for ZmWAK between two responses. It is also fascinating to notice that a total 179 transcripts for TFs were shown to participate $Z m W A K$-mediated defense response, including NAC, bZIP, bHLH, WRKY, MYB, GRAS, and other transcription family, indicating a strong reprogramme of downstream pathways. For instance, WRKY33, an important transcription factor for necrotrophic pathogens was overreprensented in ZmWAK-mediated basal response while decreased after $S$. reilianum invasion (Zheng et al. 2006). In contrast to the ZmWAK-associated basal response, typical transcripts for biotic stress response, such as SA-induced pathogenesis-related proteins, RLKs, chitinase, glutathione $S$ transferase, and production of reactive oxygen species, were highly up-regulated in the ZmWAK-associated defense response. DEGs that were repressed included those for cell-wall synthesis, cell organization, vesicle transport, and signal transduction (calcium signaling, MAPK cascade, G-protein signaling). However, in contrast to what has been reported for MPK6 in the AtWAK-associated defense response, MEK1, an upstream activator of MPK4, was upregulated in the ZmWAK-associated defense response (Huang et al. 2000). We speculate that ZmWAK activated a new MAPK pathway in head-smut defense response.

With regard to metabolic pathways, genes related to biosynthesis of terpenoids, phenylpropanoids, and lignin were significantly up-regulated, whereas genes involved in biosynthesis of sucrose and fatty acids were down-regulated, suggesting a general induction of defense-related compounds. Additionally, upregulation of glycolysis, along with repression of the tricarboxylic acid (TCA) cycle, suggested that maize cells respond to infection by predominantly making use of glycolysis rather than the TCA cycle for energy provision. A large fraction of induced transcripts were also targeted to new BINs as present in protein degradation through the ubiquitination pathway, mitochondrial electron transport (NADH dehydrogenase, cytochrome $c$ oxidase, apocytochrome b), ATPases, and ATP synthesis. Thus, upon $S$. reilianum infection, ZmWAK repressed mesocotyl growth and initiated a plant resistance response typical for defense against biotrophic fungi.

$S$. reilianum invasion also broke the balance of phytohormones. Genes for auxin transport and response (AUX, GH3, PIN, and $S A U R$ ), ABA biosynthesis (NCED3 and NCED9) and response (ABI and $H A I)$, JA biosynthesis (AOS) and signaling (JAZ), ET biosynthesis (ACC synthase), and ET-responsive transcription factors of the ERF/AP2 family were all down-regulated, whereas genes for SA $(P A L)$ and GA biosynthesis $(G A 3)$ were up-regulated.

Arabidopsis AtBAG6 is a plant-specific calmodulin-binding protein and a cell-death regulator. Notably, BAG1 and BAG6 - the two main plant apoptosis regulators-exhibited unique expression pattern in Huangzao4R. $B A G$ genes were overexpressed in Huangzao4R but had undergone a drastic decrease upon $S$. reilianum infection, which was not observed in Huangzao4. Moreover, $\mathrm{Ca}^{2+}$ signaling/calmodulin proteins had expression patterns similar to those of BAG proteins, which were induced during the $Z m W A K$-associated basal response but repressed during the $Z m W A K$-associated defense response. Changes in mRNAs encoding BAG6 and $\mathrm{Ca}^{2+}$ signaling/calmodulin proteins hint at a potential cell-death control mechanism governed by ZmWAK. We hypothesize that ZmWAK regulates the activities of BAG proteins and calmodulin to maintain cells in an antideath state in noninfected plants, whereas
ZmWAK promotes apoptosis via downregulation of BAG proteins to release cells from the antideath state and activate intrinsic apoptotic signaling upon $S$. reilianum infection. But we failed to detect an expression change of Atgs upon $S$. reilianum infection in Huangzao4, perhaps because autophagy was weak in Huangzao4 at 7 DAS and the number of cells that had undergone autophagy was limited.

\section{Metabolic switch is regulated by $\mathrm{ZmWAK}$.}

Transcriptomic analysis implicated the $Z m W A K$-associated defense response in the expression of numerous genes related to metabolism. Liquid chromatography-coupled mass spectrometry (LC-MS) enabled comprehensive and quantitative analysis of metabolite fluctuations in the two infected NILs and their noninfected controls. A metabolite was considered enriched or depleted when the intracellular concentration changed by more than 1.2 -fold with $P<0.01$. The relative changes for all metabolites are visualized in a Venn diagram and heatmap (Fig. 5).

In noninfected plants, ZmWAK introgression altered concentrations of 64 metabolites, including 39 that were increased and 25 that were decreased (Supplementary Table S5). In comparison with Huangzao4, Huangzao4R had elevated levels of nucleotides and fatty acids. In line with the transcriptome data, the content of certain phytohormones, like auxin, zeatin, $\mathrm{ABA}$, and JA, were increased. The accumulation of phenylpropanoids might be a consequence of downregulated PAL for SA biosynthesis. Likewise, higher content of GA12, which lies at the initial branch point of GA biosynthesis, is possible, due to an outcome of repression of downstream GA biosynthesis. With regard to secondary metabolites, seven flavonoids were increased, whereas 13 were decreased.

The concentrations of 73 metabolites in Huangzao4R were altered in response to $S$. reilianum infection compared with 46 in Huangzao4. After filtering out 23 metabolites with a common trend of change between the two NILs, 50 altered metabolites (five metabolites changed in opposite trends between the two NILs) were unique to Huangzao4R (Supplementary Table S6). A striking number of amino acids were at lower concentrations in infected relative to noninfected Huangzao4R, whereas this was the case for only three amino acids in infected Huangzao4, implying a reduced carbon/nitrogen flux for amino acid biosynthesis in Huangzao4R after $S$. reilianum infection. Likewise, nucleotide and fatty-acid levels were lower in the infected than noninfected Huangzao4R. The concentrations of metabolites involved in the TCA cycle, including glutaric acid, aconitic acid, citrate, isocitrate, and malic acid, were remarkably lower in infected Huangzao4R as well. Glucose concentrations were generally much lower in the infected than noninfected Huangzao4R, whereas glucose 6-phosphate and fructose 1,6-bisphosphate concentrations were higher after infection. Changes in the concentrations of metabolic intermediates for both glycolysis and the TCA cycle are consistent with the previous transcriptomic data, i.e., that glycolysis rather than the TCA cycle replenishes cellular ATP in response to $S$. reilianum infection. For flavonoids, an increasing trend was generally observed. Analysis of phytohormones revealed a relatively low content for each of JA, ABA, and auxins after infection, whereas the SA level increased, which is consistent with our observation in transcriptomic analyses that the $Z m W A K$-associated defense response resulted in downregulation of JA biosynthesis but promotion of the biotrophic defense response.

\section{DISCUSSION}

Prior to the floral transition and internode expansion, the SAM is located just above the mesocotyl, and this architectural 
feature renders the mesocotyl a vital entryway for $S$. reilianum to access SAMs. Syringe infection of the SAM with a hyphae culture is an effective way to experimentally generate head smut in maize (Ghareeb et al. 2011), but this approach is timeconsuming and bypasses the mesocotyl-the crucial tissue that determines head-smut resistance. Considering the pathogenic mechanism of $S$. reilianum, the passage of this pathogen through the mesocotyl may be the decisive factor for head-smut pathogenesis. We suggest that inspection of mesocotyls at the seedling stage and assessment of the SAM invasion rate would be a time-saving means of discriminating susceptible from resistant varieties.

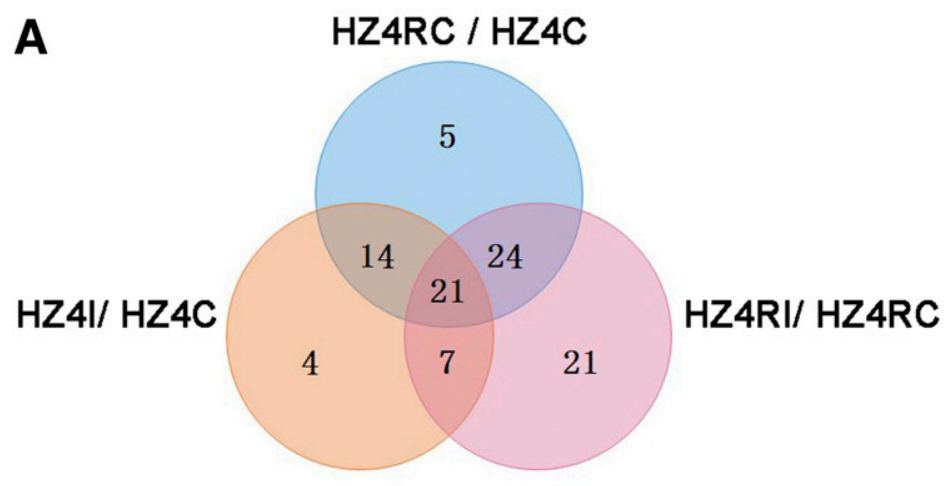

B
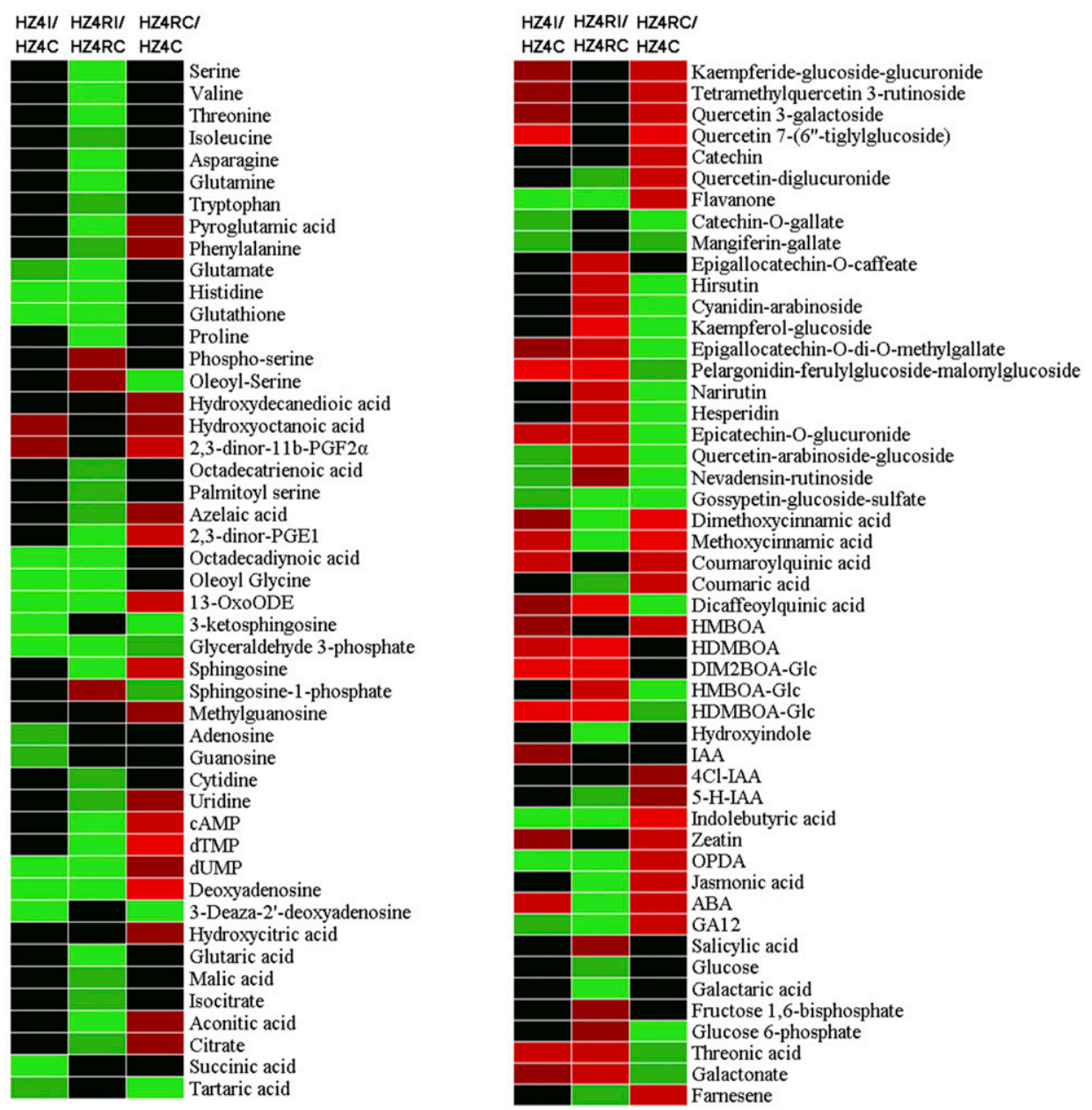

$\begin{array}{lllllll}-1 & -0.5 & -0.25 & 0 & 0.25 & 0.5 & 1\end{array}$

Fig. 5. Analysis of metabolites Huangzao4 and Huangzao4R with or without Sporisorium reilianum infection. A, Venn diagram illustrating the number of metabolites whose levels changed significantly in three pairs of samples, i.e., HZ4C and HZ4RC, HZ4I and HZ4C, and HZ4RI and HZ4RC (fold change >1.2, $P<0.05)$ and the overlapping metabolites among the three comparisons. B, Heatmap showing all metabolites whose levels increased or decreased significantly in at least one of the three comparisons. Fold changes were $\log _{2}$-transformed, and the data represent the average from six biological replicates. $\mathrm{HZ} 4 \mathrm{C}=$ noninfected Huangzao4, HZ4RC = noninfected Huangzao4R, HZ4I = infected Huangzao4, and HZ4RI = infected Huangzao4R. 
In the current study, cytological analysis provided convincing evidence that cell death modes control the outcome of the interaction between a biotrophic fungus and host. Before the floral transition, $S$. reilianum propagates in a biotrophic mode, relying on living cells for nutrient acquisition. Thus, AL-PCD in Huangzao4R blocks pathogenesis, whereas the prosurvival process of autophagy in Huangzao4 facilitates fungal colonization. Growing research over the past decades have drawn a picture of the important role of BAG proteins in plant biotic and abotic stress response, particularly in cell-death control, in which BAG6 is well identified and characterized. Upon overexpression of AtBAG6 in yeast, the cells exhibited normal growth in glucose-containing medium but underwent apoptosis in galactose-containing medium (Kang et al. 2006). An atbag6 mutant showed enhanced susceptibility to necrotrophic Botrytis cinerea (Doukhanina et al. 2006). Cleavage of AtBAG6 by two aspartyl proteases resulted in autophagy and enhanced resistance to $B$. cinerea ( $\mathrm{Li}$ et al. 2016). In our study, the $\mathrm{ZmBAG}$ genes are preinduced and undergo a drastic decrease upon $S$. reilianum infection, which expression pattern is unique in Huangzao4R. It is conceivable to infer that ZmWAK exerts its specific role in dictating the expression of $Z m B A G$ genes and that downregulation of $Z m B A G$ genes could prevent them from being cleaved or inducing autophagy.

The well-established Arabidopsis molecular model suggests that WAK proteins act at the front line of plant cell defense, where they sense and respond to changing environmental conditions. Recognition of pectin or OGs by WAK proteins provides a mechanism by which plant cells can switch between growth and the defense response. Consistent with previous studies, global transcript profiling along with LC-MS-based metabolite profiling of the two NILs we used provide compelling evidence of functional trade-offs in the ZmWAKassociated response to a changing environment. If ZmWAK acts similarly to Arabidopsis WAK (AtWAK), our findings

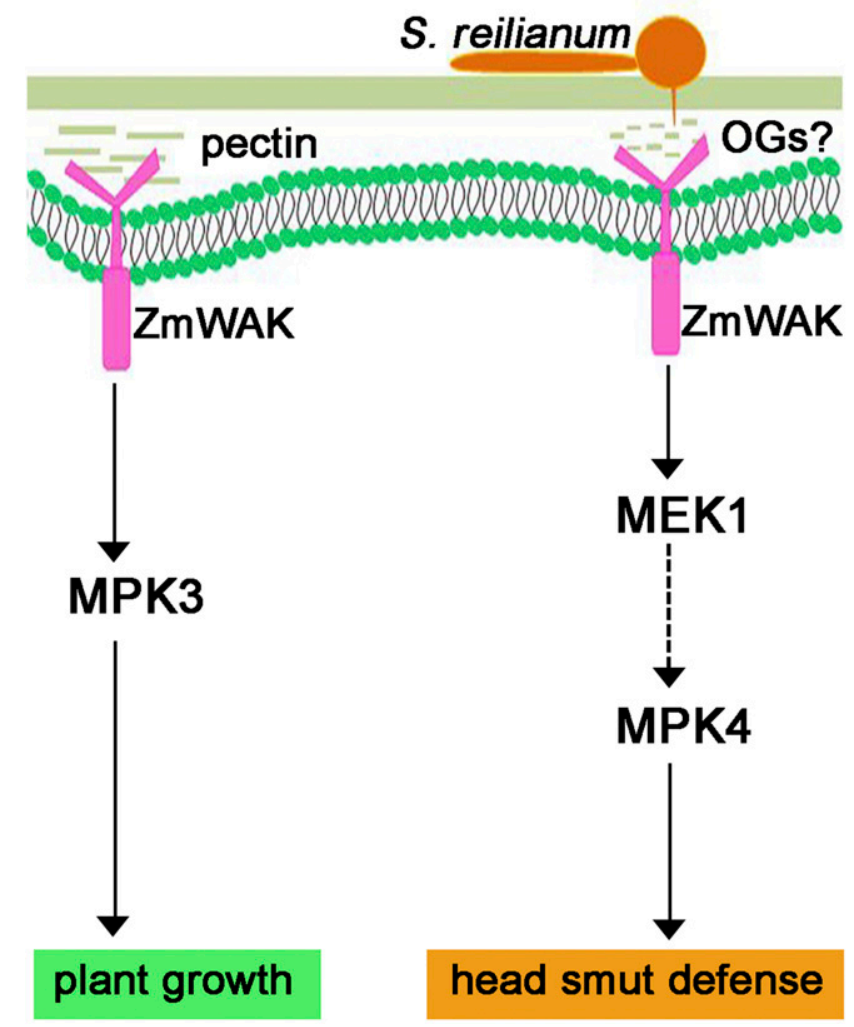

Fig. 6. Mechanism of ZmWAK-mediated head-smut resistance. could help to define the mechanism of $Z m W A K$-mediated headsmut resistance (Fig. 6). It is quite possible that $\mathrm{ZmWAK}$ binds pectin to promote growth and depress the defense response in the absence of pathogen. Invading $S$. reilianum may secrete polygalacturonase to release OGs from the cell wall. Perception of OGs by ZmWAK thus downregulates cell growth and upregulates the SA-dependent defense response, thereby promoting AL-PCD to prevent $S$. reilianum from further invasion. This growth-defense trade-off requires coordination among multiple pathways, including signal transduction, transcription factors, hormone metabolism, production of reactive oxygen species, reallocation of primary and secondary metabolites, and mobilization of the PCD machinery. What is impressive is if such a broad spectrum of responses were modulated by one gene, ZmWAK. Knowing how ZmWAK signaling transduct downstream might broaden our understanding of the mechanisms.

Concerning resistance genes, plants have always had the dilemma of whether to promote growth or defense, as enhanced defense often has a yield penalty. ZmWAK, with its plasticity of adaption to environmental fluctuations, could promote growth in noninfected plants and switch to the defense response upon $S$. reilianum infection. This fine-tuning of the trade-off between growth and defense makes $Z m W A K$ an ideal target for breeding programs. Although $Z m W A K$ contributes to the normal growth of plants, the lack of ZmWAK in Huangzao4 does not substantively impact growth. We speculate that this is a consequence of the redundancy of WAK families in maize (Zuo et al. 2015). Indeed, transcriptome data revealed a relatively greater abundance of other WAK family members in Huangzao4 than Huangzao4R, although the absolute abundance of other WAK proteins was much less than that of ZmWAK. Functional compensation from other WAK family members may also explain the partial resistance observed for Huangzao4.

It has long been recognized that the complex crosstalks of hormones optimize plant response to diverse environmental cues and balance the resistance response and fitness penalty. SA and JA/ET have been shown to function antagnostically in the defense against specific pathogen with different lifstyles. SA is required for the regulation of biotrophic pathogen defense; wheras JA/ET are positive regulators of plant defense against necrotrophic pathogens (Glazebrook 2005). SA has also been reported to inhibit growth via repression of auxin signaling, and elevated auxin signaling mostly leads to enhanced susceptibility to biotrophic pathogens (Huot et al. 2014; RobertSeilaniantz et al. 2011). It is noteworthy that the hormone homeostasis state was different between Huangzao4 and Huangzao4R under the noninfected condition. Huangzao4R showed higher expression of JA-, ET-, ABA-, and auxinresponsive genes while showing lower expression of GA and $\mathrm{SA}$, as compared with Huangzao4. Intriguingly, S. reilianum infection disturbed the original balance of hormonal crosstalk in Huangzao4R, leading to the global alteration of hormone biosynthesis and the expression of related genes. S. reilianum growth restriction in Huangzao4R was accompanied by the accumulation of SA and activation of SA signaling marker gene PR proteins, suggesting that SA-dependent biotrophic pathogen resistance also exerts its role in mesocotyl defense against S. reilianum. Consistent with the negative crosstalk between SA and JA, JA content was markedly decreased and the expression of key genes for JA and ET biosynthesis and signaling were strongly down-regulated. In addition to the classic defense hormone, other hormone pathways have also been affected by $S$. reilianum infection. ABA and auxin content and signaling were decreased, whereas GA content and signaling increased. It is surprising to find that $Z m W A K$ controls all of the key genes for these hormones, making it logical to infer that ZmWAK 
stands at the hub of the intricate hormonal networks and modulates the entire hormone network, rather than merely one specific hormone-related pathway, to precisely respond to environmental changes. ZmWAK introgression changed the state of hormonal equilibrium in Huangzao4, in which growthpromoting auxin was overrepresented to benefit plant growth. Upon pathogen attack, defense hormone SA was increased to switch plants into a defense mode.

Given our findings for $Z m W A K$, we conclude that this gene functions as a hub in the growth and defense trade-off to optimize plant fitness. Still, the following five questions must be addressed. First, is ZmWAK a receptor for both pectin and OGs? Second, how does upstream signaling lead to a switch between basal and defense response pathways downstream? Third, how does ZmWAK alone orchestrate such a broad range of transcriptional and metabolic responses? Fourth, how does ZmWAK impact the abundance of BAG proteins? Finally, do any pathogen components participate in the ZmWAK-associated defense response? Our understanding of $Z m W A K$-associated head-smut resistance is rather rudimentary and numerous aspects await exploration.

\section{MATERIALS AND METHODS}

Plant growth and inoculation.

The $\mathrm{F}_{1}$ hybrid was made between the donor line Ji1037 and recurrent parent Huangzao4, followed by continuous backcrossing to Huangzao4 to generate $\mathrm{BC}_{9} \mathrm{~F}_{1}$ generation. The $\mathrm{BC}_{9} \mathrm{~F}_{1}$ plant with the shortest $Z m W A K$ donor segment $(152 \mathrm{~kb})$ was selfed twice to produce a pair of NILs, Huangzao4R (with $Z m W A K$ ) and Huangzao4 (without $Z m W A K$ ), identified by using a codominant marker MZAI (Supplementary Table S7). We further used a GoldenGate 6KSNP chip (Illumina) to examine the two NILs, and the result showed the they have $99.65 \%$ identity in their genetic backgrounds.

The field infection study was performed in Gongzhuling, Jilin Province, China. Galls from susceptible lines were collected to prepare teliospores. After sowing, seeds were covered with contaminated soil containing $0.1 \%$ teliospores. Disease severity was scored at the filling stage when symptoms fully appeared.

Indoor infection was performed in an illumination incubator under a 16-h-light and 8-h-dark cycle at $28^{\circ} \mathrm{C}$ and $60 \%$ relative humidity. Seeds were soaked in $2 \% \mathrm{NaClO}$ for $30 \mathrm{~min}$ and were rinsed three times with distilled water. Soil was autoclaved at $121^{\circ} \mathrm{C}$ for $20 \mathrm{~min}$ prior to sowing seeds. Sterilized seeds were sown in sterile soil (mock treatment) or soil containing $0.1 \%$ spores.

\section{WGA staining.}

WGA staining was carried out as described by Ghareeb et al. (2011). Bottom mesocotyls were harvested, were cut into thin sections, and were placed into 2-ml tubes. Samples were rinsed with distilled water once and were then soaked in $10 \% \mathrm{KOH}$ overnight. Samples were then rinsed three times with distilled water and were incubated with WGA stain solution $(10 \mathrm{mg}$ of WGA per milliliter, $0.02 \%$ ( $\mathrm{vol} / \mathrm{vol}$ ) Tween 20 in phosphatebuffered saline [PBS], $\mathrm{pH}$ 7.4) for 30 min under vacuum infiltration. After washing three times with PBS, samples were observed under an Olympus FV 1000 fluorescence microscope with excitation at $488 \mathrm{~nm}$ and emission at 500 to $540 \mathrm{~nm}$.

\section{Trypan blue staining.}

Seedlings were collected 7 DAS. Removal of all leaves and roots yielded intact mesocotyls. Mesocotyls were then incubated at $100^{\circ} \mathrm{C}$ for $5 \mathrm{~min}$ in trypan blue staining solution, which consisted of two volumes ethanol plus one volume stock solution $(0.02 \mathrm{~g}$ of trypan blue, $10 \mathrm{~g}$ of phenol, $10 \mathrm{ml}$ of glycerol, $10 \mathrm{ml}$ of lactic acid, $10 \mathrm{ml}$ of water). After further staining overnight, trypan blue was removed and was replaced with chloral hydrate several times, for bleaching before inspection. Samples were cut and were observed under a light microscope.

\section{Analysis of SAM invasion rate.}

SAMs were harvested from infected NILs at 21 DAS. Total RNA was extracted using the plant Total RNA kit (Tiangen), and first-strand cDNA was synthesized using the Easy Script first-strand cDNA synthesis kit (Transgen). The presence or absence of $S$. reilianum was assessed with PCR and the S. reilianum-specific primer SRac (sr11345). PCR cycling was as follows: $95^{\circ} \mathrm{C}$ for $5 \mathrm{~min}$, followed by 35 cycles of $95^{\circ} \mathrm{C}$ for $30 \mathrm{~s}, 60^{\circ} \mathrm{C}$ for $30 \mathrm{~s}$, and $72^{\circ} \mathrm{C}$ for $30 \mathrm{~s}$, with a final $72^{\circ} \mathrm{C}$ for 10 min. PCR products were examined in $1 \%$ agarose gels, after staining with ethidium bromide.

\section{Scanning electron microscopy.}

Mesocotyl samples were fixed for $>2 \mathrm{~h}$ in $2.5 \%$ glutaraldehyde in PBS at 0 to $4^{\circ} \mathrm{C}$, were rinsed three times with the same buffer, and were immersed in $1.0 \%$ osmium tetroxide in PBS for $2 \mathrm{~h}$. After rinsing twice with PBS, samples were dehydrated in a graded series of ethanol $(30,50,70,80,90$, and $100 \%)$, were subjected to critical-point drying, and were coated with gold. Scanning electron microscopy images of the patterned gold samples were acquired using a Hitachi S-3400N.

\section{Transmission electron microscopy.}

Mesocotyl samples were fixed for $>2 \mathrm{~h}$ in $2.5 \%$ glutaraldehyde in PBS at 0 to $4^{\circ} \mathrm{C}$, were rinsed three times in the same buffer, and were immersed in $1.0 \%$ osmium tetroxide in PBS for $2 \mathrm{~h}$. After rinsing three times with PBS, samples were dehydrated in a graded series of acetone $(30,50,70,80,90$, and $100 \%)$. Samples were then embedded in epoxy resin. Ultrathin sections were cut with a Leica UC6 ultramicrotome and were then stained with uranyl acetate and lead citrate. Finally, samples were examined and were photographed using transmission electron microscopy (JEOLJEM-1230).

\section{MDC staining.}

Mesocotyls were stained with MDC as described by Kabbage et al. (2013). Seedlings were incubated for $30 \mathrm{~min}$ in $0.05 \mathrm{mM}$ MDC in PBS. After washing three times with PBS, samples were observed with the Olympus FV 1000, using the UV channel.

\section{RNA sequencing.}

Infected and noninfected mesocotyls were taken 7 DAS with two replicates. Total RNA was extracted using TRIzol (Invitrogen) and were purified with the PureLink RNA mini kit (Invitrogen). RNA quality was assessed, using the Agilent RNA 6000 Pico kit, prior to preparation of the sequence library. A cDNA library for each sample was constructed using "mRNA Seq sample prep kit" (Illumina). Sequencing of each cDNA library was carried out on an Illumina HiSeq 2500 paired-end 100-bp (PE 100) system. Raw sequencing data were evaluated by FAST-QC. Total reads were mapped to maize B73 RefGen_V2 (Schnable et al. 2009), using Bowtie and TopHat software. Expression values were determined as fragments per kilobase exon per million mapped reads, using Cufflinks. DEGs between samples were defined as having a $\log _{2}$-fold change $>1$ and false discovery rate $<0.01$. Functional annotation of DEGs was conducted with MAPMAN.BIN tool. The heatmap for DEGs was generated by Hemi (Deng et al. 2014). 


\section{Real-time PCR.}

Infected and noninfected mesocotyls were taken 7 DAS. Total RNA was extracted and the first-strand cDNA was synthesized as described above. Quantitative PCR was performed on a Rotor-Gene Q 6000, using SYBR green (Takara). The conditions for PCR amplification were as follows: $95^{\circ} \mathrm{C}$ for $5 \mathrm{~min}$, followed by 40 cycles of $95^{\circ} \mathrm{C}$ for $10 \mathrm{~s}$ and $60^{\circ} \mathrm{C}$ for $30 \mathrm{~s}$. The fold change in target gene expression was normalized to expression levels of tubulin and GAPDH, and relative expression was determined by the cycle threshold $\left(2^{-\Delta \Delta \mathrm{Ct}}\right)$ method. The mean and standard deviation were calculated from three biological repeats.

\section{LC-MS-based metabolomics analysis.}

Infected or noninfected mesocotyls $(150 \mathrm{mg})$ were harvested 7 DAS, and six replicates were set up. Samples were frozen immediately in liquid nitrogen and were stored at $-80^{\circ} \mathrm{C}$ until extraction. Mesocotyls were ground in liquid nitrogen and were mixed with $400 \mu \mathrm{l}$ methanol and water (1:1). After $3 \mathrm{~min}$ of vigorous agitation, samples were centrifuged at $12,000 \times g$ at $4^{\circ} \mathrm{C}$ for $10 \mathrm{~min}$. The supernatant was transferred to a vial, and a $100-\mu l$ sample was subjected to ultraperformance liquid chromatography (UPLC)-coupled quantitative time-of-flight (Q-TOF) mass spectrometry.

The supernatant was separated with chromatography using an Agilent 1290 Infinity UHPLC system (Agilent Technologies). A Waters UPLC HSS T3 C18 column $(1.8 \mu \mathrm{m} 100 \times$ $2.1 \mathrm{~mm}$ ) was used for the reverse-phase separation. The mobile phase consisted of $0.1 \%$ formic acid (buffer A), and $0.1 \%$ formic acid in acetonitrile (buffer B). Gradient elution consisted of $2 \%$ B for $2 \mathrm{~min}, 2$ to $95 \%$ B from 2 to $17 \mathrm{~min}$, and $95 \%$ $\mathrm{B}$ from 17 to $19 \mathrm{~min}$. The total run time was $25 \mathrm{~min}$ including a 6-min period to re-equilibrate at $2 \% \mathrm{~B}$. The flow rate was $350 \mu \mathrm{l} / \mathrm{min}$, and the injection volume was $3 \mu \mathrm{l}$.

An Agilent 6538 UHD and Accurate-Mass (Q-TOF) mass spectrometer was operated in positive ion mode and negative ion mode with a capillary voltage of $4 \mathrm{kV}$ in positive ion mode and $3.5 \mathrm{kV}$ in negative ion mode, drying gas flow of 11 liters per min, and a gas temperature of $350^{\circ} \mathrm{C}$. The nebulizer pressure was set at $45 \mathrm{psi}$. The fragmentation voltage was set at $120 \mathrm{~V}$ and skimmer voltage at $60 \mathrm{~V}$. All analyses were obtained by means of an automated calibrant delivery system using a dualnebulizer ESI source that introduces a low flow $(100 \mathrm{ml} / \mathrm{min})$ of a reference solution (Agilent Technologies), which contains the internal reference masses at $\mathrm{m} / \mathrm{z} 121.0509,922.0098$ in positive ion mode and $\mathrm{m} / \mathrm{z}$ 112.9856, 1,033.9881 in negative ion mode to ensure mass accuracy and reproducibility. The mass range was set at $\mathrm{m} / \mathrm{z} 100$ to 1,100 .

Raw data obtained in instrument-specific format (.d) were converted to common data format (.mzData) files using Agilent Mass Hunter qualitative analysis (B.03.01) software that eliminated isotope interferences. The program XCMS was used to extract raw data signals (peak identification and integration), correct retention time, and for automatic integration and deconvolution analysis (best mass spectrometry fragmentation) in R software platform. Data were collected in centroid mode, and metabolites were identified by matching $\mathrm{m} / \mathrm{z}$ values in the METLIN database with mass error $<5 \mathrm{ppm}$. The list of peaks (deprotonated $\mathrm{m} / \mathrm{z}$ values) along with corresponding retention time, putative annotation, and peak intensity in a matrix were exported to Microsoft Excel for further data processing.

\section{ACKNOWLEDGMENTS}

This work was financially supported by the National Key Research and Development Program of China (grant numbers 2016YFD0101002 and 2016YFD0101803).

\section{LITERATURE CITED}

Brutus, A., Sicilia, F., Macone, A., Cervone, F., and De Lorenzo, G. 2010. A domain swap approach reveals a role of the plant wall-associated kinase 1 (WAK1) as a receptor of oligogalacturonides. Proc. Natl. Acad. Sci. U.S.A. 107:9452-9457.

de Oliveira, L. F., Christoff, A. P., de Lima, J. C., de Ross, B. C., SachettoMartins, G., Margis-Pinheiro, M., and Margis, R. 2014. The wallassociated kinase gene family in rice genomes. Plant Sci. 229:181-192.

Decreux, A., and Messiaen, J. 2005. Wall-associated kinase WAK1 interacts with cell wall pectins in a calcium-induced conformation. Plant Cell Physiol. 46:268-278.

Deng, W., Wang, Y., Liu, Z., Cheng, H., and Xue, Y. 2014. HemI: A toolkit for illustrating heatmaps. PLoS One 9:e111988.

Dickman, M. B., and Fluhr, R. 2013. Centrality of host cell death in plantmicrobe interactions. Annu. Rev. Phytopathol. 51:543-570.

Dickman, M. B., Park, Y. K., Oltersdorf, T., Li, W., Clemente, T., and French, R. 2001. Abrogation of disease development in plants expressing animal antiapoptotic genes. Proc. Natl. Acad. Sci. U.S.A. 98:6957-6962.

Doukhanina, E. V., Chen, S., van der Zalm, E., Godzik, A., Reed, J., and Dickman, M. B. 2006. Identification and functional characterization of the BAG protein family in Arabidopsis thaliana. J. Biol. Chem. 281: 18793-18801.

Ghareeb, H., Becker, A., Iven, T., Feussner, I., and Schirawski, J. 2011. Sporisorium reilianum infection changes inflorescence and branching architectures of maize. Plant Physiol. 156:2037-2052.

Glazebrook, J. 2005. Contrasting mechanisms of defense against biotrophic and necrotrophic pathogens. Annu. Rev. Phytopathol. 43:205-227.

He, Z. H., Cheeseman, I., He, D., and Kohorn, B. D. 1999. A cluster of five cell wall-associated receptor kinase genes, Wak1-5, are expressed in specific organs of Arabidopsis. Plant Mol. Biol. 39:1189-1196.

Huang, Y., Li, H., Gupta, R., Morris, P. C., Luan, S., and Kieber, J. J. 2000. ATMPK4, an Arabidopsis homolog of mitogen-activated protein kinase, is activated in vitro by AtMEK1 through threonine phosphorylation. Plant Physiol. 122:1301-1310.

Huot, B., Yao, J., Montgomery, B. L., and He, S. Y. 2014. Growth-defense tradeoffs in plants: A balancing act to optimize fitness. Mol. Plant 7: $1267-1287$.

Hurni, S., Scheuermann, D., Krattinger, S. G., Kessel, B., Wicker, T., Herren, G., Fitze, M. N., Breen, J., Presterl, T., Ouzunova, M., and Keller, B. 2015. The maize disease resistance gene Htn1 against northern corn leaf blight encodes a wall-associated receptor-like kinase. Proc. Natl. Acad. Sci. U.S.A. 112:8780-8785.

Kabbage, M., Williams, B., and Dickman, M. B. 2013. Cell death control: The interplay of apoptosis and autophagy in the pathogenicity of Sclerotinia sclerotiorum. PLoS Pathog. 9:e1003287.

Kang, C. H., Jung, W. Y., Kang, Y. H., Kim, J. Y., Kim, D. G., Jeong, J. C., Baek, D. W., Jin, J. B., Lee, J. Y., Kim, M. O., Chung, W. S., Mengiste, T., Koiwa, H., Kwak, S. S., Bahk, J. D., Lee, S. Y., Nam, J. S., Yun, D. J., and Cho, M. J. 2006. AtBAG6, a novel calmodulin-binding protein, induces programmed cell death in yeast and plants. Cell Death Differ. 13:84-95.

Kim, K. S., Min, J. Y., and Dickman, M. B. 2008. Oxalic acid is an elicitor of plant programmed cell death during Sclerotinia sclerotiorum disease development. Mol. Plant-Microbe Interact 21:605-612.

Kohorn, B. D. 2016. Cell wall-associated kinases and pectin perception. J. Exp. Bot. 67:489-494.

Kohorn, B. D., Johansen, S., Shishido, A., Todorova, T., Martinez, R., Defeo, E., and Obregon, P. 2009. Pectin activation of MAP kinase and gene expression is WAK2 dependent. Plant J. 60:974-982.

Kohorn, B. D., Kohorn, S. L., Todorova, T., Baptiste, G., Stansky, K., and McCullough, M. 2012. A dominant allele of Arabidopsis pectin-binding wall-associated kinase induces a stress response suppressed by MPK6 but not MPK3 mutations. Mol. Plant 5:841-851.

Li, Y., Kabbage, M., Liu, W., and Dickman, M. B. 2016. Aspartyl proteasemediated cleavage of BAG6 is necessary for autophagy and fungal resistance in plants. Plant Cell 28:233-247.

Liu, Y., and Bassham, D. C. 2012. Autophagy: Pathways for self-eating in plant cells. Annu. Rev. Plant Biol. 63:215-237.

Martinez, C., Roux, C., and Dargent, R. 1999. Biotrophic development of Sporisorium reilianum $f$. sp. zeae in vegetative shoot apex of maize. Phytopathology 89:247-253.

Martinez, C., Roux, C., Jauneau, A., and Dargent, R. 2002. The biological cycle of Sporisorium reilianum f.sp. zeae: An overview using microscopy. Mycologia 94:505-514.

Reape, T. J., and McCabe, P. F. 2008. Apoptotic-like programmed cell death in plants. New Phytol. 180:13-26. 
Reape, T. J., and McCabe, P. F. 2010. Apoptotic-like regulation of programmed cell death in plants. Apoptosis 15:249-256.

Robert-Seilaniantz, A., Grant, M., and Jones, J. D. 2011. Hormone crosstalk in plant disease and defense: More than just jasmonate-salicylate antagonism. Annu. Rev. Phytopathol. 49:317-343.

Schnable, P. S., Ware, D., Fulton, R. S., Stein, J. C., Wei, F., Pasternak, S., Liang, C., Zhang, J., Fulton, L., Graves, T. A., Minx, P., Reily, A. D., Courtney, L., Kruchowski, S. S., Tomlinson, C., Strong, C., Delehaunty, K., Fronick, C., Courtney, B., Rock, S. M., Belter, E., Du, F., Kim, K., Abbott, R. M., Cotton, M., Levy, A., Marchetto, P., Ochoa, K., Jackson, S. M., Gillam, B., Chen, W., Yan, L., Higginbotham, J., Cardenas, M., Waligorski, J., Applebaum, E., Phelps, L., Falcone, J., Kanchi, K., Thane, T., Scimone, A., Thane, N., Henke, J., Wang, T., Ruppert, J., Shah, N., Rotter, K., Hodges, J., Ingenthron, E., Cordes, M., Kohlberg, S., Sgro, J., Delgado, B., Mead, K., Chinwalla, A., Leonard, S., Crouse, K., Collura, K., Kudrna, D., Currie, J., He, R., Angelova, A., Rajasekar, S., Mueller, T., Lomeli, R., Scara, G., Ko, A., Delaney, K., Wissotski, M., Lopez, G., Campos, D., Braidotti, M., Ashley, E., Golser, W., Kim, H., Lee, S., Lin, J., Dujmic, Z., Kim, W., Talag, J., Zuccolo, A., Fan, C., Sebastian, A., Kramer, M., Spiegel, L., Nascimento, L., Zutavern, T., Miller, B., Ambroise, C., Muller, S., Spooner, W., Narechania, A., Ren, L., Wei, S., Kumari, S., Faga, B., Levy, M. J., McMahan, L., Van Buren, P., Vaughn, M. W., Ying, K., Yeh, C. T., Emrich, S. J., Jia, Y., Kalyanaraman, A., Hsia, A. P., Barbazuk, W. B., Baucom, R. S., Brutnell, T. P., Carpita, N. C., Chaparro, C., Chia, J. M., Deragon, J. M., Estill, J. C., Fu, Y., Jeddeloh, J. A., Han, Y., Lee, H., Li, P., Lisch, D. R., Liu, S., Liu, Z., Nagel, D. H., McCann, M. C., SanMiguel, P., Myers, A. M., Nettleton, D., Nguyen, J., Penning, B. W., Ponnala, L., Schneider, K. L., Schwartz, D. C., Sharma, A., Soderlund, C., Springer, N. M.,
Sun, Q., Wang, H., Waterman, M., Westerman, R., Wolfgruber, T. K., Yang, L., Yu, Y., Zhang, L., Zhou, S., Zhu, Q., Bennetzen, J. L., Dawe, R. K., Jiang, J., Jiang, N., Presting, G. G., Wessler, S. R., Aluru, S., Martienssen, R. A., Clifton, S. W., McCombie, W. R., Wing, R. A., and Wilson, R. K. 2009. The B73 maize genome: Complexity, diversity, and dynamics. Science 326:1112-1115.

Verica, J. A., and He, Z. H. 2002. The cell wall-associated kinase (WAK) and WAK-like kinase gene family. Plant Physiol. 129:455-459.

Williams, B., Kabbage, M., Kim, H. J., Britt, R., and Dickman, M. B. 2011. Tipping the balance: Sclerotinia sclerotiorum secreted oxalic acid suppresses host defenses by manipulating the host redox environment. PLoS Pathog. 7:e1002107.

Zhang, S., Chen, C., Li, L., Meng, L., Singh, J., Jiang, N., Deng, X. W., He, Z. H., and Lemaux, P. G. 2005. Evolutionary expansion, gene structure, and expression of the rice wall-associated kinase gene family. Plant Physiol. 139:1107-1124.

Zheng, Z., Qamar, S. A., Chen, Z., and Mengiste, T. 2006. Arabidopsis WRKY33 transcription factor is required for resistance to necrotrophic fungal pathogens. Plant J. 48:592-605.

Zuo, W., Chao, Q., Zhang, N., Ye, J., Tan, G., Li, B., Xing, Y., Zhang, B., Liu, H., Fengler, K. A., Zhao, J., Zhao, X., Chen, Y., Lai, J., Yan, J., and $\mathrm{Xu}, \mathrm{M}$. 2015. A maize wall-associated kinase confers quantitative resistance to head smut. Nat. Genet. 47:151-157.

\section{AUTHOR-RECOMMENDED INTERNET RESOURCES}

MAPMAN.BIN tool: http://www.gabipd.de/projects/MapMan

METLIN database: https://metlin.scripps.edu/index.php 